\title{
THIRD WORLD PETROLEUM CONGRESS
}

$\mathrm{W}$ ITH nearly three hundred papers from leading petroleum technologists in every oil-producing or oil-refining country, the Third World Petroleum Congress which met in The Hague during May 28June 6 covered the whole range of the sciences concerned with the petroleum industry-geology, geophysics, engineering in all its branches and chemistry, as well as statistics, documentation and economics.

At least sixty sessions were held and all were well attended. In general, discussion was lively and to the point, being restricted only by the time factor, which was somewhat limited by the time taken to read in two languages the instructions regarding discussion.

Geology and Geophysics. In the session on the origin and migration of oil, when papers were presented by Margaretha Brongersma-Sanders (University of Leyden), by I. A. Breger and W. L. Whitehead (Massachusetts Institute of Technology), and by C. E. ZoBell (Scripps Institute of Oceanography), the consensus of opinion was that there is need for generally accepted definitions and methods of analysis of organic matter occurring in geological formations. This is particularly true for crude oils in relation to migration and classification studies, but also applies to maltha, asphalt, asphaltic, pyrobitumen, etc. The setting up of a committee to study these matters was recommended, and it was suggested that it should consist of Prof. V. C. Illing (United Kingdom), M. Louis (France), G. R. Schultze (Germany), H. M. Smith (United States), and K. van Nes (The Netherlands). It was also resolved that the Permanent Council of the World Petroleum Congress take the initiative in clarifying the terms relating to oil migration.

Several papers on palæontology and sedimentology were discussed in two sessions, an important contribution being that of T. F. Grimsdale, who proposed geological correlation on a world-wide scale. In comparing Venezuelan and Middle East rock sequences of the Tertiary, Mr. Grimsdale uses pelagic (open ocean) foraminifera. From this subsection of the geological section came two resolutions. The first, based on a paper by D. J. Doeglas, stressed the desirability of regional investigations into sedimentary deposits and environments, as proposed in Project 5 of the American Association of Petroleum Geologists; but such studies should not be limited to the Gulf Coast area. The second resolution recorded the opinion that world-wide correlations could be established in the Upper Cretaceous and in the Tertiary formations by means of the pelagic foraminifera.

Regional geology of oilfield areas was the subject of several papers, a session with four papers on the Middle East being concerned mainly with Persia. There were also sessions on Italy, with seven papers, and on Mexico.

In the subsection on geophysics, there were nine papers dealing with seismological, gravitational, and electrical methods.

Drilling and Production. In this section there were about fifty papers covering all aspects of this important branch of the industry. In the session on drilling technique, the papers were mainly devoted to mechanical processes associated with the drilling of oil wells. Two resolutions concerned the standard testing of casing centralizers, and a proposal that the American Petroleum Institute consider standard specifications for integral-joint casing.

Opening the session on drilling, completion and production technique, the chairman pointed out that the papers clearly showed how technique has advanced since the early days of the industry. For several of the papers a considerable mathematical background was necessary.

Discussion on the type of mud used in completing oil wells demonstrated that oil-well performance could be materially improved by choice of the proper drilling fluid. The general opinion was that oil-base muds are equal or superior to oil-in-water emulsion muds, or to normal clay-water muds for well completions, but that water alone is probably the best fluid as far as drilling speed is concerned.

The value of laboratory investigations for the development and improvement of drilling and production technique was evident in the discussion on several papers. Investigations into the properties of the cements used in deep wells were reported in a paper from the Institut Français du Pétrole, and it was recommended that blast furnace slag cements should be used for the purpose. Work on the effect of particle size on the physical properties of drilling mud makes it possible to predict the viscosity of a clay-base fluid for a given concentration of solids, provided particle-size distribution is known.

A new approach to the knowledge of the behaviour of crude oil emulsions was outlined in a paper on a universal size-frequency distribution law for emulsion particles. When water and oil are produced together, their separation causes difficulties in practice. A formula has been derived statistically for describing droplet size distribution and has proved its value also in other oil-industry operations.

The importance of additional recovery from oilfields was pointed out in several papers, and methods of secondary recovery were reviewed. There were also several reports of laboratory investigations. It was also stated that in Digboi notable increases in production-rates have been obtained by washing waxy wells with kerosine. The effect is to soften, rather than to dissolve, wax in and near the well.

Physical Refining Processes. In this section an interesting discussion on calculations in relation to distillation apparatus and information was given from the Polytechnic Institute of Brooklyn of a new laboratory apparatus for the determination of equilibrium flash curves of complex mixtures. This apparatus is a modified type of recirculating equilibrium still, is compact, of low initial cost, and is expected to provide an improved basis for calculations.

Chemical Refining Processes. The session on hydrogenation and hydrocarbon synthesis was attended by a large audience, and discussion centred mainly on the development of synthesis. It seems that vapourphase processes are likely to receive competition from the liquid-phase processes now being developed. Although fluid-catalyst technique is largely applied in the vapour-phase processes, the fixed-bed process still received much attention. An improved large fixed-bed plant is shortly to come into operation in Germany. 
The development in Germany of the one-stage process for destructive hydrogenation of crude oil to gasoline with new catalysts occupied most of the discussion as regards hydrogenation. Combined hydrogenation and catalytic or thermal cracking processes are likely to be used on a large scale in Germany.

In the session on catalytic reforming, an interesting paper was that by E. V. Murphree on a fluid hydroforming process, which is claimed to produce gasoline of improved octane rating. The fluid-process plant was said to cost 40 per cent less than fixed-bed units.

A paper on a new process for the polymerization of gaseous olefins to motor gasoline gave rise to interesting comparisons with the well-established solid phosphoric acid process.

The importance of sulphur removal and recovery from petroleum products was reflected in the five papers in the session on chemical treating processes. Methods for sulphur removal ranged from conventional soda sweetening of gasoline to hydrofining - selective hydrogenation of sulphur compounds. The latter process has attractive prospects.

Petroleum Chemicals. This section was concerned with the properties and the application of petroleumbased chemicals. Thus, in the detergent session, the five papers related to the extraordinary growth of petroleum detergents in the United States, where such materials now account for 55 per cent of the total American production of synthetic detergents. It was clear that the market outside the United States cannot be forecast from American developments, and it appeared that although the alkyl aryl sulphonates lead in the detergent field, alkyl sulphates, when prepared from petroleum, are likely to challenge their position. The influence on detergent properties of the hydrocarbon constitution was specially discussed.

In regard to biocides, it was stated that our know. ledge of the chemical and physical compositions of mineral oils is still insufficient to guarantee that a certain oil would be suitable for agricultural use without previous field testing.

Composition of Petroleum. During the discussion of a group of papers on pure hydrocarbons, attention was directed to the fact that international exchange of data on these materials could be improved. It was therefore recommended that the extension of such exchange of research data should be explored. The discussion dealt mainly with the suitability of different criteria for determining hydrocarbon purity, and with the applicability of various physical con stants for identifying and analysing hydrocarbons.

Properties of crude oils were considered from two aspects : first, the classification and evaluation of crude oils ; and secondly, their commercial evaluation. It was considered that characterizing factors now used do not correlate with chemical composition but mainly summarize the physical properties. It would be convenient, although it did not appear possible, to combine the two aspects into one simple factor. It was concluded that knowledge of the chemical composition of crude oils necessitates a more complicated scheme of analysis, which would require more uniformity in methods of investigation in order to correlate results obtained all over the world.

Ten papers in this section were devoted to various aspects of the constitution of petroleum. The investigation of the complex mixtures of which petroleum fractions are composed has been simplified by modern methods of group analyses. In regard to determination of oil composition by spectrographic analysis, it was considered that the emphasis should be more on so-called type analyses.

Utilization. Papers in this section dealt with the utilization of such petroleum products as engine fuels, lubricants, heating fuels and bitumen.

In the session on gasoline engine fuels, the reduction of engine friction was suggested as an alternative to higher compression ratios in order to reduce fuel consumption. It was also pointed out that there is room for improvement in automatic control of spark advance. In the overall economic picture, increased cost of high-compression engines should be weighed against increased cost of producing higher anti-knock gasoline.

The gas turbine fuel session discussed three aspects of the general subject. First to be considered was the complicated position which exists because the severe cold-test requirement of aircraft turbine fuel specifications limits the supply sources. Opinions varied widely as to the extent to which engine and fuel should contribute to the solution of the problem. Secondly, on the use of boiler-type fuels in stationary and marine gas turbines, the economics are not favourable without a cheap fuel. Difficulties due to varying percentages and composition of ash from the fuel are still serious. Finally, the Pescara system as applied to locomotives was dealt with. In this system a free-piston diesel is combined with a turbine, through which it develops its power and which functions simultaneously as a variable-torque transmission element.

Four papers on motor lubricants all dealt with some aspect of additives ; the general comment was that the large amount of research being carried out is insufficiently stressed. It was also suggested that viscosity-index improvers may not be effective at high rates of shear, the effect of pressure not having been investigated. Industrial and special lubricants and electrical oils were also discussed.

Construction Materials. This section dealt mainly with materials, construction, equipment and corrosion. One interesting proposal made by two French authors is for a method of heat exchange whereby the two fluids are in direct contact. It was stated that it is effective where there is no danger of emulsions being formed due to the nature of the oil or of the cooling water.

Miscellaneous. Sections 9 and 10 dealt respectively with transport, storage and distribution of petroleum products, and with economics, statistics, documentation, education and training.

\section{HUMAN PROBLEMS OF THE SCOTTISH HIGHLANDS}

$\mathrm{N}$ an article in a recent issue of the American 1 Scientist (39, No. 2; April 1951), Dr. Fraser Darling discusses recent concepts of human ecology. Human ecology, he suggests, deals with the structure of animal communities which man dominates and their development through the ecological principles of succession. With Paul Sears he believes that "the social function of ecology is to provide a scientific basis whereby man may shape the environment and his relations to it as he expresses himself in and through his culture patterns". To-day it would not 